\title{
PENGARUH KUALITAS PELAYANAN, TAMPILAN MUSEUM DAN MANAJEMEN KOLEKSI TERHADAP KEPUASAN WISATAWAN MONUMEN YOGYA KEMBALI
}

\author{
Tuti Panghastuti \\ NIDN. 0503076402 \\ panghas64@gmail.com \\ Dosen STIE "Pariwisata API" Yogyakarta
}

\begin{abstract}
Museums are more important than ever before. They play a substantial role in people's leisure activities and belong to one of the most importance tourist attractions. The visitors have a strong effect on local economies, especially in touristic locations. Not surprisingly therefore more and more museums are founded usually in spectacular buildings. This research employs three dimention of service quality to understand the factors underlying tourist satisfaction of 'Monumen Yogya Kembali'.These dimentions investigated are namely Service Quality, The Appearance of the Museum and Collection Management.

Sampling has been conducted at the Monumen Yogya Kembali between October 1225 th 2015. Convenient random sampling has been employed to 100 respondent. Through a 4 point Likert-type scale, tourists' expectations of a perfect service provider has been compared with the practices Monumen Yogya Kembali to determine if there are any gaps. Service Quality, the Appearance of the Museum, and Collection Management' has been analyzed together with its effects on tourist' satisfaction through a regression analysis.

Linear regression analysis is conducted to test the research model. The regression modelthat explains the satisfaction variable via Service Quality, the Appearance of the Museum, and Collection Management factors is tested. Accordingly, tested regression model is meaningful $(F: 34,651, p<0.001)$ and independent variables canexplain the $50,5 \%$ of change in the satisfaction variable. Closer analysis of the modelparameters suggests Service Quality, the Appearance of the Museum, and Collection Management variables have a significantly positive effect on satisfaction.
\end{abstract}

Key word : Monumen Yogya Kembali, Service Quality, The Appearance of the Museum, Collection Management, Tourist, Satisfaction.

\section{PENDAHULUAN}

Kerjasama antara UNESCO dan Pemerintah Indonesia untuk Revitalisasi Museum seluruh Indonesia tertuang dalam buku Panduan Praktis Revitalisasi Museum. Buku panduan ini merupakan hasil evaluasi, diskusi dan konsultasi antara UNESCO di Jakarta dan Direktorat Museum berkaitan dengan kondisi keseluruhan Museum yang ada di Indonesia mulai dari identifikasi pemasalahan hingga target pengukurannya. Revitalisasi mencakup enam aspek, yaitu karakter fisik, manajemen museum, jaringan antar museum, program, kebijakan dan pencitraan.Implementasi keenam aspek ini dijadwalkandari tahun 2011-2014 untuk seluruh museum di Indonesia. Adapun pelaksanaan keenam aspek tersebut mengacu pada tiga pilar kebijakan permuseuman di Indonesia, yaitu mencerdaskan bangsa, mengidentifikasi dan 
membentuk kepriba-dian bangsa (karakter bangsa), serta menanam-kan konsep ketahanan nasional dan wawasan nusantara (UNESCO, 2011).

Kiprah UNESCO di berbagai negara berkai-tan dengan Museum memberikan prioritas dalam meningkatkan peran museum sebagai pusat pengetahuan dan pendidikan, serta meningkatkan praktek pelestarian dan perlin-dungan warisan budaya. Upaya dilakukan dengan meningkatkan kualifikasi staf museum secara profesional di bidang mana-jemen museum dan pelestarian warisan budaya, atas dasar manual dan publikasi UNESCO, hingga membangun kerangka interaksi mitra dan kerjasama internasional (ICOM, 2012).

Empat tahun revitalisasi Museummuseum di Indonesia telah dilaksanakan, kini saatnya Pengunjung 'menikmati' hasil kerja keras yang berupa kreatifitas dan inovasi dalam memenuhi kebutuhan pelanggan maupun wisatawan. Setiap aspek kualitas pelayanan mendapatkan sentuhan modern dan profesional, baik dari segi fisik, manajemen staf, kebijakan, jaringan kerja sama dan administrasi. Representasi dari kegiatan revitalisasi ini, penulis mengangkat keberadaan Museum Monumen Yogya Kembali sebagai kajian evaluasi berdasar persepsi pengunjung Museum pasca pelaksanaan program.

Monumen Yogya Kembali yang sering disingkat menjadi Monjali berlokasi di dusun Jongkang, kelurahan Sariharjo, kecamatan Ngaglik, kabupaten Sleman. Monjali mulai dibangun pada tanggal 29 Juni 1985.Monumen ini berisi sejarah perjuangan tentara dan rakyat Yogyakarta melawan Belanda, khususnya perang gerilya merebut kembali kota Yogyakarta pada tanggal 1 Maret 1949 yang dipimpin oleh Letnan Kolonel Soeharto dan Sri
Sultan Hamengku Buwono IX. Monumen berbentuk tumpeng ini memiliki tinggi 31,8 meter, berdiri di lahan seluas 5,6 hektar. Halaman Monumen ini merupakan plasa yang luas, yang kerap digunakan sebagai tempat pelaksanaan berbagai acara.

Tabel 1 mwnunjukkan jumlah pengunjung Museum Monumen Yogya Kembali dalam 4 tahun terakhir berfluktuasi. Untuk mengetahui secara detail di bawah ini tabel yang menunjukkan angka-angka jumlah kunjungan per bulan selama tahun 2011 hingga 2014. Dari tabel baris dapat diketahui rerata kunjungan tertinggi pada bulan Desember mencapai 58.908 orang, kemudian disusul Juni 58.616 orang, sedangkan rerata kunjungan terendah di bulan September berjumlah 11.904 dan Februari dengan 12.918 pengunjung. Dari tabel kolom memperlihatkan rerata kunjungan tertinggi pada tahun 2012 sebesar 28.032, dan terlihat kembali meningkat di tahun 2014 yang berhasil mencapai 27.774 pengunjung. Sejak tahun 2012 hingga 2014 pengunjung per tahun Monumen Yogya Kembali telah mencapai angka di atas 300.000 orang. Dari data di atas berdasarkan jumlah pengunjung, menunjukkan bahwa tiga tahun terakhir kinerja pengelola Monumen Yogya kembali dalam kondisi yang baik.

Penelitian ini secara khusus menganalisis pengaruh kualitas pelayanan, tampilan museum, manajemen koleksi terhadap kepuasan wisatawan di monumen yogya kembali. Hasil observasi pendahuluan di lapangan member-kan gambaran bahwa (1) ruangan gedung yang luas mem-butuhkan interior yang selalu terpelihara, baik itu dinding, lantai, atap, perleng-kapan,suhu ruangan dan penerangan, (2) ketidakhadiran salah satu atau beberapa faktor tersebut dapat menimbulkan kesan 'menakutkan, misalnya 
seperti kurangnya penerangan atau udara yang lembab, (3) data jumlah kunjungan wisata dari tahun ke tahun belum menunjukkan kenaikan yang konsisten dan (4) data jumlah kunjungan berfluktuasi relatif tinggi hanya disaat musim liburan. Oleh karena itu penyelesaian masalah pokok secara khusus diarahkan untuk menganalisis dan menjeaskan (1) pengaruh kualitas pelayanan terhadap kepuasan wisatawan monumen yogya kembali (2) pengaruh tampilan museum terhadap kepuasan wisatawan monumen yogya kembali, (3) pengaruh manajemen koleksi terhadap kepuasan wisatawan monumen yogya kembali dan (4) pengaruh kualitas pelayanan, tampilan museum dan manajemen koleksi berpengaruh terhadap kepuasan wisatawan

\section{REVIEW LITERATURE}

Menurut The World Museum Community (ICOM), museum adalah lembaga yang mengoleksi, melestarikan, penelitian, danpameran, untuk tujuan studi, pendidikan, dan bukti masa lalu dari perjuangan suatu masyarakat dan lingkungan. Oleh karena itu, peran museum bukan hanya untuk melin-dungi koleksi dan warisan budaya, tetapi juga mencakup peningkatan aksesibilitas dan pergeseranfokus dari konservasi terhadap kunjungan.Oleh karena itu, museum dapat dilihat sebagai aset penting yang memberikan kontribusi untuk pengem-bangan pariwisata berkelanjutan dengan menggunakan konteks pariwisata budaya dan warisan.

Tabel 1. Pengunjung Monumen Yogya Kembali Tahun 2011-2014

\begin{tabular}{|c|c|c|c|c|c|c|}
\hline & $\mathbf{2 0 1 1}$ & $\mathbf{2 0 1 2}$ & $\mathbf{2 0 1 3}$ & $\mathbf{2 0 1 4}$ & Jumlah & Rerata \\
\hline JAN & 17.434 & 32.969 & 30.650 & 38.278 & 119.331 & $\mathbf{2 9 . 8 3 3}$ \\
\hline FEB & 13.513 & 15.779 & 12.598 & 9.781 & 51.671 & $\mathbf{1 2 . 9 1 8}$ \\
\hline MAR & 11.379 & 15.950 & 24.908 & 23.465 & 75.702 & $\mathbf{1 8 . 9 2 6}$ \\
\hline APR & 11.085 & 14.476 & 15.400 & 15.421 & 56.382 & $\mathbf{1 4 . 0 9 6}$ \\
\hline MEI & 39.115 & 61.712 & 59.806 & 51.433 & 212.066 & $\mathbf{5 3 . 0 1 7}$ \\
\hline JUN & 51.960 & 57.282 & 58.152 & 67.070 & 234.464 & $\mathbf{5 8 . 6 1 6}$ \\
\hline JUL & 17.657 & 19.678 & 9.758 & 8.742 & 55.835 & $\mathbf{1 3 . 9 5 9}$ \\
\hline AGU & 2.445 & 15.689 & 18.842 & 15.879 & 52.855 & $\mathbf{1 3 . 2 1 4}$ \\
\hline SEP & 15.642 & 11.793 & 8.786 & 11.395 & 47.616 & $\mathbf{1 1 . 9 0 4}$ \\
\hline OKT & 13.214 & 13.762 & 15.718 & 17.334 & 60.028 & $\mathbf{1 5 . 0 0 7}$ \\
\hline NOV & 8.592 & 15.832 & 15.686 & 18.522 & 58.632 & $\mathbf{1 4 . 6 5 8}$ \\
\hline DES & 59.301 & 61.460 & 58.904 & 55.966 & 235.631 & $\mathbf{5 8 . 9 0 8}$ \\
\hline Jumlah & 261.337 & 336.382 & 329.208 & 333.286 & & \\
\hline Rerata & $\mathbf{2 1 . 7 7 8}$ & $\mathbf{2 8 . 0 3 2}$ & $\mathbf{2 7 . 4 3 4}$ & $\mathbf{2 7 . 7 7 4}$ & & \\
\hline Sum & & & & \\
\hline
\end{tabular}

Sumber: http://monjali6789.blogspot.com/-Diolah

Sementara Markovick et al. (2013) menyatakan bahwa Museum menghadapi suatu dilema antara banyaknya jumlah pengunjung dan risiko atau dampak kerusakan yang ditimbulkan oleh banyaknya jumlah pengunjung. Pembangunan berkelanjutan (sustainable development) sering dikaitkan dengan alam lingkungan hidup, maka di masa depan industri pariwisata tergantung pada 
perlindungan kawasanlingkungan, warisan, dan sumber daya budaya. Selain itu, keberlanjutan berkaitan dengan kemampuan tujuan untuk menjaga kualitas fisik, sosial,sumber daya budaya, dan lingkungan.

Dalam rangka memenuhi peran Museum di atas, Museum harus fokus pada pemenuhan kebutuhan dan harapan dari pengunjung. Konsep Service Quality, memberikan kesadaran adanya gap antara harapan dan kinerja. Parasuraman et al. (1988), memberikan sebuah kontribusi besar dalam konseptualisasi kualitas pelayanan dan pengukuran. Pengertian Kualitas Pelayanan merujuk pada persepsi konsumen dalam membandingkan antara harapan konsumen dan kinerja pelayanan yang dirasakan. Pengertian lain menyatakan bahwa evaluasi kualitas bukan semata-mata terletak pada hasil dari pelayanan tersebut, namun termasuk proses pelayanan hingga diterima konsumen. Dengan demikian premis dasar dari Kualitas Pelayanan adalah interaksi antara konsumen dan organisasi penyelenggara jasa.

Tampilan Museum menjadi pokok perhatian dalam program revitalisasi Museum yang dicanangkan oleh UNESCO dan merupakan tahap pertama yang dituangkan dalam buku pedoman. Tampilan umum ini meliputi antara lain: (1) komplek Museum, (2) bagian luar gedung Museum, (3) bagian dalam gedung Museum. (4) Peragaan objek dan display, (5) pelayanan penerimaan tamu.

Monumen Yogya Kembali yang dirancang dalam filosofi Jawa, baik dalam hal lokasi, tampilan dan koleksi penuh simbol makna, berusaha mengakomodasi perkembangan masyarakat khususnya di bidang wisata.Komplek Monjali dibangun arena bermain anak dengan nama Taman Pelangi. Taman Pelangi menempati bagian depan halaman Museum dan mulai ramai dikunjungi mulai sore hingga malam hari, dengan jenis permainan untuk anak-anak, seperti trampolin, sepeda tandem, memasuki balon di atas air.Sebagaimana umumnya arena permainan anak tersedia food court bagi pengantarnya.

Manajemen Koleksi (Collections Management) merupakan salah satu fungsi kegiatan pokok Museum.Kelengkapan Museum ini sebagai daya tarik utama seseorang maupun kelompok mengunjungi Museum, di mana sebagai pusat studi dan kajian ilmu. Kegiatan yang meliputi Manajemen Koleksi antara lain: (1) penyimpanan, (2) perawatan, (3) pencatatan dan inventarisasi, (4) Keamanan, (5) perolehan benda budaya, (6) penghapusan koleksi, (7) peminjaman dan (8) peralatan (UNESCO, 2011).

Secara umum manajemen koleksi adalah berupaya mengamankan koleksi baik dari gangguan suhu, serangga maupun manusia.Sebuah museum harus memiliki ruang yang cukup untuk menyimpan koleksi benda-benda.Desain museum harus dirancang sedemikian rupa agar dapat memberikan iklim yang akan melestarikan benda koleksi, mampu mengendalikan suhu, kelembaban, dan cahaya.. Lay out penataan benda-benda koleksi harus diatur sedemikian rupa, sehingga arus pengunjung ketika menikmati benda koleksi tidak mengganggu keberadaan koleksi.

Zeithaml dan Bitner (2003: 85) mengemukakan bahwa kepuasan adalah konsep yang jauh lebih luas daripada hanya sekedar penilaian dari kualitas pelayanan, tetapi juga dipengaruhi oleh faktor lain, seperti misalnya faktor situasi, latar belakang individu dan kualitas produk. Kualitas pelayanan (jasa), adalah tingkat keunggulan yang diharapkan dan pengendalian atas tingkat keunggulan tersebut untuk memenuhi keinginan 
pelanggan.Dengan demikian ada 2 faktor utama yang mempengaruhi kualitas pelayanan (jasa), yaitu : expected servicedanperceived Service. Apabila pelayanan (jasa) yang diterima atau dirasakan (perceived service)sesuai dengan yang diharapkan (expected service), maka kualitas pelayanan (jasa) dipersepsikan baik dan memuaskan.

\section{METODE PENELITIAN}

\section{Desain Penelitian}

Penelitian ini bermaksud mengkaji dan menganalisis pengaruh Kualitas Pelayanan, Tampilan Museum dan Manajemen Koleksi terhadap Kepuasan Wisatawan Monumen Yogya Kembali.

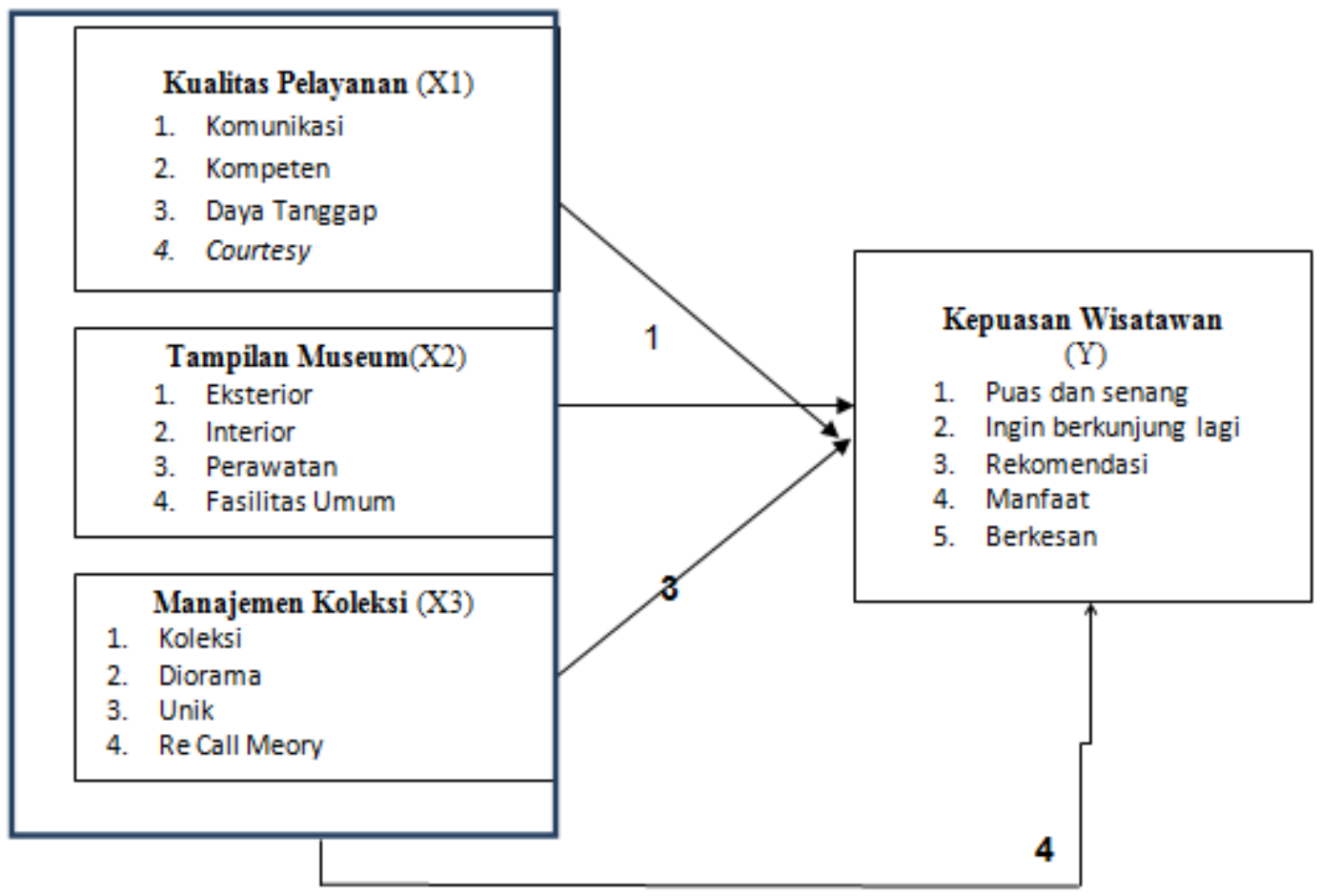

Gambar .1 Desain Penelitian

Keterangan Alur :

1 : Kualitas Pelayanan (X1) terhadap Kepuasan Konsumen (Y)

2 : Tampilan Museum (X2) terhadap Kepuasan Konsumen (Y)

3 : Manajemen Koleksi (X3) terhadap Kepuasan Konsumen (Y)

4 : X1, X2 dan X3 terhadap Y

Populasi, Sampel Penelitian dan Teknik Sampling

Dari data kunjungan selama empat tahun terakhir rata-rata pengunjung Monumen Yogya Kembali dari 2011-2014 sekitar 315.053 orang per tahun. Rata-rata jumlah pengunjung bulan Oktober dalam empat tahun sebanyak15.007 orang.

Pada populasi yang jelas jumlah penarikan sampel dapat digunakan rumus
Slovin. Data populasi diambil berdasarkan data kunjungan rerata bulan Oktober dalam empat tahun sebesar 15.007 orang, dan menghasilkan responden sebanyak 100 orang.

Teknik pengambilan sampel yang digunakan dalam penelitian ini adalah accidental sampling yaitu suatu teknik penentuan sampel berdasarkan kebetulan, yaitu siapa saja yang dianggap peneliti 
dapat dipakai sebagai sampel, jika dipandang orang yang kebetulan ditemui itu cocok untuk dijadikan sebagai sumber data yaitu sepanjang kriteria pengunjung Monumen Yogya Kembali telah berusia 15 tahun, yang berkunjung pada bulan Oktober 2015 dan dianggap cakap untuk mengisi kuesioner.

Uji Kelayakan Instrumen

\section{Uji Validitas Instrumen}

Uji Validitas digunakan untuk memilih item-item pertanyaan yang relevan untuk dianalisis. Uji Validitas dilakukan dengan melihat korelasi antar skor masingmasing item pertanyaan dengan skor total (Corrected item total correlation). Kevalidan suatu instrumen dinilai dengan cara membandingkan nilai $r$ tabel dengan nilai $r$ hasil. $r$ hasil ditunjukkan dari nilai Corrected Item -Total Correlation. $\mathrm{r}$ tabel diperoleh dari tabel nilai $\mathrm{r}$ kritis pada $\mathrm{df}=$ $n-2$ pada tingkat toleransi $(\alpha)$ tertentu. $n$ adalah jumlah sampel yang diambil dalam uji validitas. Apabila nilai korelasi dari setiap pernyataan lebih besar dari nilai kritis yaitu $\mathrm{r}$ hitung $>\mathrm{r}$ tabel, maka pernyataan tersebut dapat dikatakan valid .

\section{Pengujian Reliabilitas}

Pengertian reliabilitas adalah sebuah indeks yang menunjukkan sejauh mana suatu suatu alat pengukur dapat dipercaya atau diandalkan. Uji reliabilitas ini juga merupakan suatu cara untuk melihat apakah alat ukur yang berupa kuesioner yang digunakan konsisten atau tidak. Apabila suatu alat pengukur dipakai dua kali atau lebih dan hasil pengukuran yang diperoleh konsisten, maka alat ukur tersebut reliabel.

\section{Alat Analisis}

Analisis korelasi berganda adalah analisis tentang pengaruh antara dua atau lebih variable bebas (independent variable).
Analisis regresi berganda bertujuan untuk memprediksi nilai pengaruh tiga variable bebas terhadap satu variable terikat dengan menggunakan persamaan regresi sebagai berikut :

$Y=a+B_{1} X_{1}+B_{2} X_{2}+B_{3} X_{3}$

Keterangan :

Y : Kepuasan Wisatawan

a : Konstanta

$\beta 1, \beta 2, \beta 3$ : Koefisien regresi variabel bebas

$\mathrm{X}_{1} \quad$ : Kualitas Pelayanan

$\mathrm{X}_{2} \quad$ : Tampilan Museum

$\mathrm{X}_{3} \quad$ : Manajemen Koleksi

\section{HASIL PENELITIAN DAN \\ PEMBAHASAN}

Pengujian Hipotesis

Uji ini digunakan untuk melihat tingkat signifikan variabel independen mempengaruhi variabel dependen secara individu atau sendiri-sendiri.Pengujian ini dilakukan secara parsial dengan menggunkan uji t statistik untuk masingmasing variabel bebas, dengan tingkat kepercayaan tertentu.

Penelitian ini menggunakan program SPSS. Dengan maintenance pada box convidence level 95\%, apabila hasil regresi mempunyai signifikansi di bawah 5\% maka menolak $\mathrm{H}_{0}$ dan menerima $\mathrm{Ha}$, demikian pula apabila hasil regresi di atas $5 \%$, berarti menerima $\mathrm{H}_{0}$ dan menolak Ha.

$Y=-0,073+0,155 X_{1}+0,224 X_{2}+0,669$ $\mathbf{X}_{3}$

Berdasarkan hasil analisis regresi linier berganda yang diperoleh, maka dibuat persamaan linier berganda

\section{Hasil Uji t (Uji Signifikansi Parsial)}

Hasil uji t atau uji signifikansi parsial dilakukan untuk mengetahui pengaruh masing-masing variabel bebas terhadap 
variabel terikatnya. Hasil uji $\mathrm{t}$ pada penelitian ini sebagai berikut:

a. Pengaruh Kualitas Pelayanan (X1) terhadap Kepuasan Wisatawan (Y)

Berdasarkan hasil pengujian diperoleh t-hitung $=2,119>\mathrm{t}$-tabel 1,985 atau $\rho$ value $0,037<0,05$, maka H0 ditolak dan Ha diterima, sehingga hipotesis khusus pertama dapat diterima yang berarti Kualitas Pelayanan (X1) berpengaruh positif dan signifikan terhadap Kepuasan Wisatawan (Y) di Monumen Yogya Kembali.

b. Pengaruh Tampilan Museum (X2) terhadap Kepuasan Wisatawan (Y)

Berdasarkan hasil pengujian diperoleh t-hitung $=2,647>\mathrm{t}$-tabel 1,985 atau $\rho$ value $0,010<0,05$, maka $\mathrm{H} 0$ ditolak dan Ha diterima, sehingga hipotesis khusus kedua dapat diterima yang berarti Tampilan Museum (X2) berpengaruh positif dan signifikan terhadap Kepuasan Wisatawan(Y) di Monumen Yogya Kembali.

c. Pengaruh Manajemen Koleksi (X3) terhadap Kepuasan Wisatawan (Y)

Berdasarkan hasil pengujian diperoleh t-hitung $=6,039>\mathrm{t}$-tabel 1,985 atau $\rho$ value $0,000<0,05$, maka $\mathrm{HO}$ ditolak dan Ha diterima, sehingga hipotesis khusus ketiga dapat diterima yang berarti Manajemen Koleksi (X3) berpengaruh positif dan signifikan terhadap Kepuasan Wisatawan(Y) di Monumen Yogya Kembali.

d. Kualitas Pelayanan (X1), Tampilan Museum (X2), dan Manajemen Koleksi (X3) secara simultan berpengaruh signifikan terhadap Kepuasan Wisatawan (Y). Kesimpulan ini dibuktikan oleh $\mathrm{F}$ hitung sebesar 34,651 dengan nilai sig 0,000, maka hipotesis umum yang menyatakan "Kualitas Pelayanan, Tampilan Museum dan Manajemen Koleksi berpengaruh positif dan signifikan terhadap Kepuasan Wisatawan Monumen Yogya Kembali" diterima.

\section{Pembahasan}

\section{Pengaruh Kualitas Pelayanan terhadap Kepuasan Wisatawan}

Hasil uji hipotesis menyatakan bahwa Kualitas Pelayanan berpengaruh secara positif dan signifikan terhadap Kepuasan Wisatawan, sehingga semakin berkualitas pelayanan yang diberikan akan meningkatkan Kepuasan Wisatawan di Monumen Yogya Kembali.

Penelitian Kualitas Pelayanan ini difokuskan pada dimensi (1) Komunikasi, (2) Kompeten,(3). Daya tanggap,dan (4) Courtesy. Ke empat dimensi ini menilai bagaimana pesan Sejarah disampaikan oleh pengelola Museum kepada wisatawan sebagai generasi penerus dalam cara yang efektif, nyaman, mudah dicerna dan difahami. Hasil atau tanggapan dari wisatawan memperlihatkan bahwa, dimensi komunikasi dengan indikator pernyataan 'Komunikasi staf/karyawan secara umum baik' menempati persepsi tertinggi di hati pengunjung. Sebaliknya pada dimensi yang sama pernyataan 'Bahasa yang disampaikan mudah difahami' menempati persepsi terendah dalam variabel Kualitas Pelayanan.Penelitian ini mendukung penelitian terdahulu yang dilakukan oleh Agbor \& Eriksson (2011) yang berjudul The Relationship between Customer Satisfactionand Service Quality: a study of three Service in Umea menguji Pengaruh Kualitas Pelayanan terhadap Kepuasan Konsumen dengan objek tiga sektor jasa yang berbeda yaitu perguruan tinggi, bank dan toko. Masing-masing menggunakan 
dimensi berbeda sesuai dengan jenis pelayanannya. Hasilnya secara umum menunjukkan bahwa Kualitas pelayanan berpengaruh positif terhadap Kepuasan Konsumen, namun setiap jenis usaha mempunyai pengaruh yang berbeda dan sebagai kesimpulannya setiap jenis pelayanan hendaknya digunakan dimensi yang sesuai dengan fungsinya.

\section{Pengaruh Tampilan Museum terhadap Kepuasan Wisatawan}

Hasil uji hipotesis menyatakan bahwa Tampilan museum berpengaruh secara positif dan signifikan terhadap Kepuasan Wisatawan, sehingga semakin baik tampilan Museum akan meningkatkan Kepuasan Wisatawan di Monumen Yogya Kembali.

Penelitian memfokuskan variabel Tampilan Fisik pada dimensi (1) Eksterior, (2) Interior,(3) Perawatan,dan (4). Fasilitas Umum. Ke empat dimensi ini mengevaluasi fisik bangunan yang meliputi landscape, eksterior, interior, fasilitas pendukung yang akan memberikan perasaan nyaman, terhibur, hingga rasa takjub yang akan memvisualisasikan pesan sejarah. Pernyataan Secara umum bangunan terawat baik menempati persepsi tertinggi dalam penilaian wisatawan. Hal ini dimungkinkan pernyataan bersifat umum sehingga merupakan penilaian keseluruhan dari variabel Tampilan Museum, sehingga wisatawan cenderung memberi nilai kesimpulan, baik itu kemungkinan lebih tinggi atau lebih rendah. Pada kasus ini penilaian relatif tinggi dibanding lainnya.

Urutan skor terendah dalam penilaian responden adalah pernyataan Fasilitas umum dalam kondisi bersih. Masih terlihat kotor diberberapa sudut memang sangat mengganggu pemandangan. Hal ini tidak hanya masalah dalam pengelolaan, namun juga kebiasaan wisatawan lokal, pedagang dan pengunjung lain yang masih terbiasa buang sampah atau aksi corat coret akan mengurangi nilai kebersihan.

Variabel Tampilan Museum mempunyai karakter yang mendukung penelitian terdahulu, baik penelitian Agbor \& Errikson (2011), Markovoc et al (2013 dan Milferner et al (2009) mereka menggunakan tangible atau tampilan fisik sebagai variabel pertama dalam penelitiannya. Meskipun hasilnya menunjukkan pengaruh positif dan signifikan terhadap kepuasan, namun pengaruhnya tidak lebih kuat dibanding dimensi reliability. Berbeda dengan penelitian ini yang menunjukkan variabel Tampilan relatif kuat pengaruhnya terhadapan variabel Kepuasan Konsumen. Hasil ini mendukung penelitian Agbor \& Errikson (2011) yang menyatakan setiap jenis pelayanan membutuhkan dimensi yang berbeda yang sesuai dengan kegiatan utamanya. Dukungan ini selaran dengan penelitian Frey \& Meier (2003) yang menyatakan bahwa Museum mempunyai nilai kekayaan fisik yang sangat tinggi.

\section{Pengaruh Manajemen Koleksi terhadap Kepuasan Wisatawan}

Hasil uji hipotesis menyatakan bahwa Manajemen Koleksi berpengaruh secara positif dan signifikan terhadap Kepuasan Wisatawan, sehingga semakin baik Manajemen Koleksi akan meningkatkan Kepuasan Wisatawan di Monumen Yogya Kembali.

Penelitian Manajemen Koleksi ini difokuskan pada dimensi (1) Koleksi, (2) Diorama,(3) Unik,dan (4) Re call memory. Dari delapan indikator, pernyataan tentang Koleksi tertata rapi secara tematik dari dimensi Koleksi menempati peringkat pertama evaluasi responden berkaitan 
dengan Manajemen Koleksi. Hal ini menunjukkan bahwa mereka datang semata-mata untuk tujuan studi tentang Sejarah Perjuangan, sehingga sangat fokus pada alur sejarah baik secara tematik maupun kronologis. Aspek afeksi sangat mendukung dalam proses 'belajar sejarah' yang dibuktikan dengan skor yang tinggi pada pernyataan Koleksi mengingatkan masa lalu (dimensi recall memory). Koleksi tertata rapi secara tematik ini juga didukung oleh pernyataan bahwa Susunan diorama memperkuat pesan sejarah, kemudian tampil kembali indikator dari dimensi recall memory yaitu Koleksi memperjelas pengetahuan sebelumnya.

Tampaknya dalam hal kuantitas, variasi koleksi dan susunan (lay out) koleksi, responden tidak begitu antusias dengan kenyataan pernyataan bahwa (1) Jumlah koleksi lengkap sebagai bukti sejarah, (2) Jenis koleksi bervariasi sesuai kontek sejarah, (3) Diorama mudah dipahami, (4) Relief terstruktur dalam suatu kronologi, masing-masing mendapatkan skor yang relatif rendah

Hasil penelitian ini khususnya Manajemen Koleksi sesuai dengan penelitian Choi dan Kim (2013) The Study of the Impact of Perceived Quality and Value of Social Enterprises on Customer Satisfaction and Re-Purchase Intention menguji Pengaruh Kualitas Pelayanan dalam dimensi Nilai Fungsional yang Diterima, Nilai Emosi yang Diterima dan nilai Sosial yang Diterima terhadap Kepuasan Konsumen menunjukkan bahwa semakin tinggi nilai funsional yang dirasakan akan semakin tinggi pula nilai kepuasan konsumen. Demikian pula halnya dengan Nilai Emosi dan Sosial yang diterima.

\section{Pengaruh Kualitas Pelayanan, Tampilan Museum dan Manajemen Koleksi terhadap Kepuasan Wisatawan}

Kualitas Pelayanan, Tampilan Museum dan Manajemen Koleksi secara bersama-sama berpengaruh positif dan signifikan terhadap Kepuasan Wisatawan. Variabel Manajemen Koleksi merupakan varabel yang paling dominan dalam mempengaruhi Kepuasan Wisatawan di Monumen Yogya Kembali, kemudian pengaruh ke dua oleh Tampilan Museum, sedang pengaruh paling kecil adalah variabel Kualitas Pelayanan. Variasi dari ketiga variabel independen tersebut dapat menjelaskan variabel depedennya lebih dari $50 \%$ nya.

\section{KESIMPULAN DAN REKOMENDASI}

Berdasarkan hasil penelitian dapat disimpulkan sebagai berikut:

1. Kualitas Pelayanan berpengaruh positif dan signifikan terhadap Kepuasan Wisatawan Monumen Yogya Kembali.

2. Tampilan Museum berpengaruh positif dan signifikan terhadap Kepuasan Wisatawan Monumen Yogya Kembali

3. Manajemen Koleksi berpengaruh positif dan signifikan terhadap Kepuasan Wisatawan Monumen Yogya Kembali.

4. Kualitas Pelayanan, Tampilan Museum dan Manajemen Koleksi secara bersama-sama berpengaruh positif dan signifikan terhadap Kepuasan Wisatawan Monumen Yogya Kembali.

Agar kepuasan wisatawan dapat ditingkatkan, maka sejumlah rekomendasi yang perlu dipertimbangkan oleh pengelola Monumen Yogya Kembali sebagai berikut: 
1. Hasil analisis deskriptif pada tanggapan responden tentang variabel Kualitas Pelayanan butir 2 yang menyatakan 'Bahasa yang disampaikan mudah difahami' ternyata menghasilkan bobot nilai relatif rendah dibanding pernyataan lainnya, maka hendaknya staf/karyawan atau pemandu wisata menggunakan bahasa yang mudah difahami, terutama bila ada istilah Museum yang diperkirakan sangat jarang digunakan secara awam untuk memberikan penjelasan atau padanannya.

2. Kebersihan dan perawatan atau pemeliharaan fisik bangunan mungkin menjadi permasalahan umum yang dihadapi pengelola pariwisata. Namun tanggapan responden tentang variabel Tampilan Museum perlu diperhatikan secara serius karena bobot nilai untuk kebersihan fasilitas umum mendapatkan nilai yang relatif rendah dibandingkan dengan lainnya.

3. Dimensi Courtesy atau yang menyangkut staf/karyawan yang ramah dan sopan perlu dipertahankan mengingat tanggapan responden demikian baik dan memuaskan.

4. Monumen Yogya Kembali sebagai Monumen yang dikenal di seantero Indonesia untuk selalu 'real time' dan sigap dalam melayani pengunjung dalam segala detail mengingat ketiga variabel independen ini mampu menjelaskan $50.5 \%$ pengaruhnya terhadap Kepuasan Wisatawan Monumen Yogya Kembali. Dengan tingkat Kepuasan Wisatawan yang tinggi berarti membuka pintu untuk kunjungan yang lebih banyak, jaringan (net working) dan yang terpenting adalah memberi bekal kepada pengunjung tentang sejarah perjuangan.

\section{DAFTAR PUSTAKA}

Choi, Eun Jung and Soo-Hyun Kim. 2013. The Study of the Impact of Perceived Quality and Value of Social Enterprises on Customer Satisfaction and Re-Purchase Intention. International Journal of Smart Home, Vol. 7, No. 1, January.

Frey, B, S., and Stephan M. 2002.The

Economics of Museums.Handbook for Economics of Art and Culture. Ginsburgh and Throsby (eds.). Elsevier

Gujarati, D. 1999.Essensials of Econometrics. International Editions. Singapore: Irwin, McGraw-Hill

Hair, J. F., Rolph E. A., Ronald L. T. and William C. B. 1998.Multivariate Data Analysis. $5^{\text {th }}$ Ed. USA: Prentice-Hall Int'l

ICOM, 2012. Role of Museums in Education and Cuktural Tourism Development: Policy Brief. Ukraine.

ICOM. 2004. Running a Museum. A Practical Hand Book. Paris, Perancis

Kotler, P. 2000. Marketing Management. The Miliinium Edition. New Jersey, USA: Prentice-Hall Inc

Kumar Singh, Prabhas. 2013. Museum and Education.

OHRJ, Vol. XLVII, No. 1, pp. 7182.

Ladhari, R. 2009. Alternative Measures of Service.www.emeraldinsight.com 
Markovic, S., Sanja R, Jelena K. 2013.

https://sdoriza.wordpress.com/2010/04/02/

Museum Service Quality definisi-konseptual-variabel-definisi-

Measurement Using the Histoqual operasional-variabel/

Model.Tourism in Southern and

Eastern Europe, pp. 201-216,

Parasuraman, A., V. Zeithaml, and L.

Berry. 1988. SERVQUAL: A

Multiple Item Scale for Measuring

http://en.wikipedia.org/wiki/Metropolitan_ Museum_of_Ar

Consumer Perceptions of Service

Quality. Journal of Retailing. 64: 12-40.

Raquel Sánchez-Fernández and M. Ángeles Iniesta-Bonillo, 2007, The Concept of Perceived Value: Asystematic Review of the Research. Marketing Theory, 7: 427

Santoso, S. 2004. Buku Latihan SPSS Statistik Parametrik. Jakarta: PT Gramedia

Sekaran, U. 1992. Research Method for Business. New York: John Wiley and Sons.

Singarimbun dan Efendi.1995. Metode Peneliian Survey. Jakarta: LP3S

Umar H. 2002. Riset Pemasaran dan Perilaku Konsumen. Jakarta: Business Research Center

UNESCO \& Ministry of Culture and Tourism of the Republic of Indonesia. 2011.

UU No. 11 Tahun 2010 tentang Cagar Budaya

Zeithaml, V. A. 1988. Consumer Perception of Price, Quality and Value: A Means-End Model and Synthesis of Evidence. Journal of marketing, American Marketing Association

http://www.louvre.fr/en/history-louvre

http://www.nationalww2museum.org 